\title{
Dialister invisus sp. nov., isolated from the human oral cavity
}

\author{
J. Downes, M. Munson and W. G. Wade \\ Department of Microbiology, Dental Institute, Floor 28, Guy's Tower, Guy's Hospital, King's \\ College London, London SE1 9RT, UK
}

Correspondence

W. G. Wade

william.wade@kcl.ac.uk

\begin{abstract}
Six strains of anaerobic, Gram-negative coccobacilli isolated from the root canals of patients with endodontic infections (five strains) and from a deep periodontal pocket (one strain) were subjected to a comprehensive range of phenotypic and genetic tests and were found to comprise a homogeneous group. Following $16 \mathrm{~S}$ rRNA gene sequence analysis, they were found to be most closely related to Dialister pneumosintes, with $93 \%$ sequence similarity between the two taxa. A novel species, Dialister invisus sp. nov., is proposed. Biochemically, the species is largely unreactive and is asaccharolytic, with only traces of acetate and propionate detected as metabolic end-products. The $\mathrm{G}+\mathrm{C}$ content of the DNA of $D$. invisus strains is $45-46 \mathrm{~mol} \%$. The type strain is $\mathrm{E} 7.25^{\top}\left(=\mathrm{CCUG} 47026^{\top}=\mathrm{DSM} 15470^{\top}\right)$.
\end{abstract}

Despite the taxonomic advances of recent years, a substantial number of taxa isolated from the human oral cavity remain unnamed. For example, it has long been recognized that there is a group of anaerobic, Gram-negative, small coccobacilli that are unreactive in commonly used biochemical tests. In a study of the microflora associated with periocoronitis, four isolates of this group were isolated from three patients (Wade et al., 1991). Subsequent 16S rRNA gene sequence analysis of these strains revealed their identity to be Dialister pneumosintes (Milsom, 1997; Milsom et al., 1996). This species was originally named as 'Bacterium pneumosintes' (Olitsky \& Gates, 1921), before being transferred to the genus Dialister (Bergey et al., 1923). The species was subsequently moved to the genus Bacteroides (Holdeman \& Moore, 1970), but the name Dialister was revived by Moore \& Moore (1994). The species was formerly included in the family Bacteroidaceae, by virtue of being a Gram-negative, anaerobic bacillus, but a phylogenetic analysis of 16S rRNA gene sequences by Willems \& Collins (1995) showed that the species belonged to the Sporomusa sub-branch of the Gram-positive bacterial phylum and was closely related to the genus Veillonella.

D. pneumosintes is a frequent isolate from the oral cavity and has been implicated in periodontitis (Ghayoumi et al., 2002). It is also found at non-oral sites as part of mixed flora associated with purulent infections, including brain

Published online ahead of print on 4 July 2003 as DOI 10.1099/ ijs.0.02640-0.

Abbreviation: PRAS, pre-reduced anaerobically sterilized.

The GenBank accession number for the 16S rRNA gene sequence of Dialister invisus $\mathrm{E} 7.25^{\top}$ is $\mathrm{AY} 162469$. abscesses and bite-wound infections (Goldstein et al., 1984; Rousee et al., 2002).

The introduction of culture-independent analyses of the oral microflora and the concomitant use of 16S rRNA gene sequence analysis for identification have led to increased precision in the identification of isolates from oral infections (Dymock et al., 1996; Kroes et al., 1999; Paster et al., 2001). Such analyses have revealed that there are a number of taxa related to $D$. pneumosintes that are commonly isolated from oral infections. One of these, designated Dialister E1, was found to be the only organism detected in each of five samples obtained from chronic endodontic lesions (Munson et al., 2002).

The aim of this study was to characterize six isolates of taxon Dialister E1 by a variety of phenotypic and genetic tests. Dialister E1 strains E2.20, E3.07, E7.25 ${ }^{\mathrm{T}}, \mathrm{E} 9.48$ and E10.39 were isolated from the root canals of patients with endodontic infections. In each case, the strains were recovered together with a variety of other, predominantly anaerobic, taxa (Munson et al., 2002). Strain P2.65 was isolated from a periodontal pocket ( $8 \mathrm{~mm}$ deep) in an adult with periodontitis. D. pneumosintes ATCC $33048^{\mathrm{T}}$ was obtained from the ATCC (Manassas, VA, USA). D. pneumosintes strains E9.19 and E10.18 were isolated from endodontic infections. Strains were grown at $37^{\circ} \mathrm{C}$ on fastidious anaerobe agar (FAA; LabM) supplemented with $5 \%$ horse blood under anaerobic conditions (80:10:10, $\mathrm{N}_{2} / \mathrm{H}_{2} / \mathrm{CO}_{2}$ ). Colonial morphologies were determined using a plate microscope after 7 days incubation. Cellular morphology was recorded after Gram-staining of 3-day plate cultures. Transmission electron microscopy was used to examine the cell-wall ultrastructure as described previously (Downes et al., 2002). Fermentation tests were performed 
using pre-reduced, anaerobically sterilized (PRAS) sugars (Holdeman et al., 1977) and other biochemical tests, including metabolic end-product analysis by GC, were performed as described by Holdeman et al. (1977) and Summanen et al. (1993). In addition, Rosco diagnostic tablets (Rosco Diagnostica) were used, according to the manufacturer's instructions, to test for the following: aesculin and arginine hydrolysis, indole and urease production and fermentation of glucose, lactose, mannitol, melibiose, sorbitol and trehalose. Susceptibility to specialpotency antibiotic discs (vancomycin, $5 \mu \mathrm{g}$; kanamycin, $1 \mathrm{mg}$; colistin, $10 \mu \mathrm{g}$ ) was determined on FAA (Summanen et al., 1993). Temperature optima for growth were determined after 5 days incubation on FAA at $25,30,37,42$ and $45^{\circ} \mathrm{C}$. Profiles of whole-cell proteins were generated by SDS-PAGE using $10-15 \%$ gradient gels and the PhastSystem (Pharmacia) as described previously (Slayne et al., 1990). Enzyme profiles were generated with the Rapid ID 32A anaerobe identification kit (bioMérieux) according to the manufacturer's instructions. The $\mathrm{G}+\mathrm{C}$ content of the DNA was estimated by using an HPLC method as described previously (Wade et al., 1999). A thermal denaturation method (Huß et al., 1983) was used to determine the DNADNA relatedness between strains.

16S rRNA gene sequences were determined as described previously (Downes et al., 2002). Sequences were submitted to Ribosomal Database Project II (Maidak et al., 2001) for provisional identification using the program SEQUENCE MATCH. From the phylogenetic position indicated by SEQUENCE_MATCH, related sequences were selected from sequence databases and aligned by means of CLUSTAL X (Thompson et al., 1997). Further analysis was performed using the PHYLIP suite of programs (Felsenstein, 1993). Specifically, DNADIST was used to compare sequences, using the Jukes-Cantor algorithm, and NEIGHBOR was used to construct phylogenetic trees, which were viewed using TreeView (Page, 1996).

The 16S rRNA gene sequences of Dialister E1 strains E2.20, E3.07 and P2.65 had $>99.5 \%$ sequence similarity to that of strain E7.25 $5^{\mathrm{T}}$ over 1504 bp. The two closest matches (both $>99.5 \%$ sequence similarity) for the $16 \mathrm{~S}$ rRNA gene sequence of strain $\mathrm{E} 7.25^{\mathrm{T}}$ were Dialister isolate GBA27 and Dialister clone BS095 from subgingival plaque (Paster et al., 2001). Phylogenetic analysis revealed that the most closely related named species ( $93 \%$ sequence similarity) was $D$. pneumosintes within the family 'Acidaminococcaceae' (Fig. 1). The relatedness between DNA preparations of $\mathrm{E} 7.25^{\mathrm{T}}$ and D. pneumosintes ATCC $33048^{\mathrm{T}}$ was found to be $42 \%$.

The Dialister E1 strains were Gram-negative, obligately anaerobic, non-motile coccobacilli $(0 \cdot 3-0 \cdot 4 \times 0 \cdot 3-0 \cdot 6 \mu \mathrm{m})$, occurring singly, in pairs, in short chains and in small clumps. Their cellular morphology therefore resembled that of $D$. pneumosintes. After 7 days incubation on FAA plates, Dialister E1 colonies were $0 \cdot 5-0 \cdot 7 \mathrm{~mm}$ in diameter, circular and entire. Colony morphology varied from translucent, umbonate colonies to transparent, low-convex colonies with

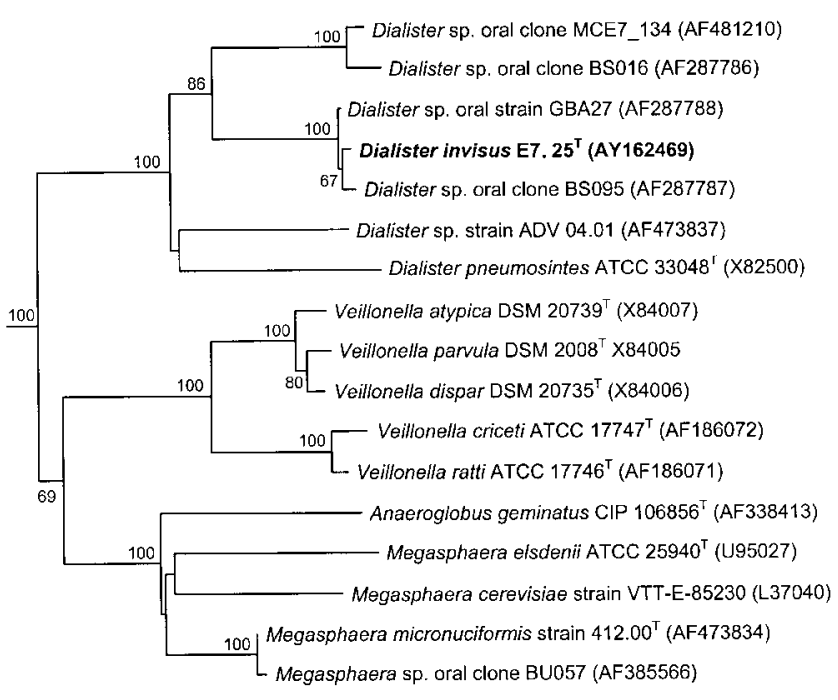

0.01

Fig. 1. Phylogenetic tree, based on $16 \mathrm{~S}$ rRNA gene sequence comparisons over 1299 aligned bases, showing the relationship between $D$. invisus sp. nov. and related species. The tree was constructed using the neighbour-joining method after distance analysis of aligned sequences. Numbers represent bootstrap values for each branch, based on data for 100 trees. Accession numbers for $16 \mathrm{~S}$ rRNA sequences are given for each strain. The scale bar shows the number of nucleotide substitutions per site.

a narrow, marginal, translucent fringe. D. pneumosintes strains exhibited larger colonies, $1 \cdot 0-1 \cdot 2 \mathrm{~mm}$ in diameter. Transmission electron microscopic examination of ultrathin sections through Dialister E1 cells showed the presence of a typical Gram-negative cell wall composed of a thin peptidoglycan layer surrounded by an outer membrane (Fig. 2).

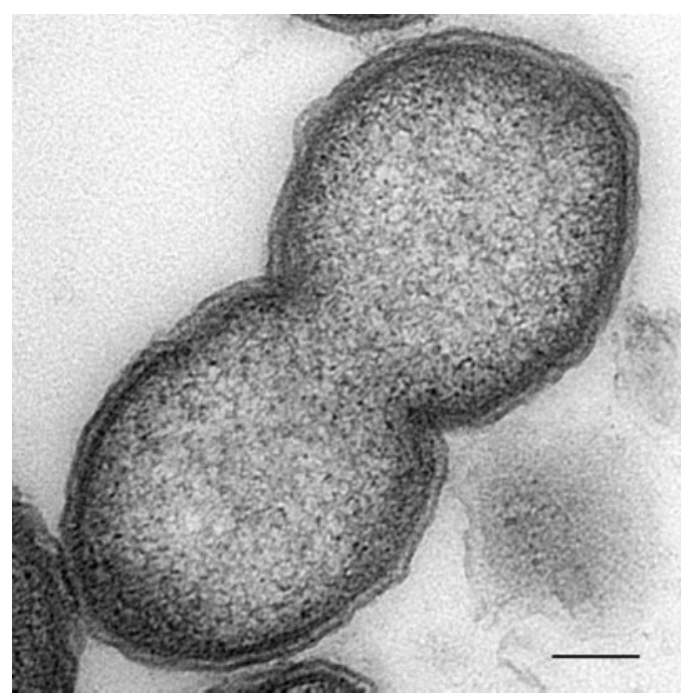

Fig. 2. Transmission electron micrograph of D. invisus $E 7.25^{\top}$ : ultrathin section showing the Gram-negative cell wall and the cytoplasmic membrane. Bar, $100 \mathrm{~nm}$. 
The growth of both Dialister E1 and D. pneumosintes strains in peptone/yeast extract broth produced only a slight turbidity that was not visibly improved by the addition of $1 \%$ (w/v) carbohydrates. Dialister E1 strains were asaccharolytic and did not ferment arabinose, cellobiose, fructose, glucose, lactose, maltose, mannitol, mannose, melezitose, melibiose, raffinose, rhamnose, ribose, salicin, sorbitol, sucrose, trehalose or xylose in the PRAS system. The use of PRAS media relies on growth of the organism in the system to determine reactions, and growth giving rise to at least $2+$ turbidity (on a scale of 0 to $4+$ ) is recommended for results to be reliable. In the case of the strains studied here, however, growth in PRAS media resulted in only slight turbidity. This lack of visible growth may not necessarily mean that the organism is not growing in the broth media, and may be due to the small size of the bacterial cells and their consequent poor lightrefractive qualities. A growth-independent system (Rosco diagnostic tablets) that utilizes preformed enzymes was used to overcome this problem. However, the results obtained from the Rosco system confirmed those from the PRAS media, in that acid was not produced from glucose, lactose, mannitol, melibiose, sorbitol or trehalose. Trace amounts of acetate and propionate were detected as end-products of metabolism in peptone/yeast extract/glucose medium. Aesculin, arginine and urea were not hydrolysed and indole and catalase were not produced. There was no growth in $20 \%$ bile. Equivalent growth occurred at 30 and $37^{\circ} \mathrm{C}$ and growth was only slightly reduced for some strains at $42^{\circ} \mathrm{C}$, whereas no significant growth was detected at 25 or $45^{\circ} \mathrm{C}$. The Dialister E1 strains were unreactive for all tests in the Rapid ID 32A identification system, resulting in a Rapid ID 32A profile of 0000000000 . D. pneumosintes strains ATCC $33048^{\mathrm{T}}$, E9.19 and E10.18 all gave a profile of 0000010000 ; the single positive reaction was for arginine arylamidase. All Dialister E1 strains were resistant to vancomycin and sensitive to kanamycin and colistin, whereas the type strain and two clinical isolates of $D$. pneumosintes were resistant to colistin, confirming the findings of Doan et al. (2000), who reported that $9 / 9$ clinical isolates of $D$. pneumosintes were resistant to colistin. The $\mathrm{G}+\mathrm{C}$ contents of the DNAs of strains E7.25 $5^{\mathrm{T}}$ and E2.20 were 45 and $46 \mathrm{~mol} \%$, respectively. The $\mathrm{G}+\mathrm{C}$ content of the DNA of D. pneumosintes ATCC $33048^{\mathrm{T}}$ was $35 \mathrm{~mol} \%$. Protein profiles of strains E2.20, E7.25 ${ }^{\mathrm{T}}$, E9.48 and D. pneumosintes ATCC $33048^{\mathrm{T}}$ are shown in Fig. 3. The profiles for E2.20, E7.25 ${ }^{\mathrm{T}}$ and E9.48 were virtually identical, but showed significant differences with respect to that of $D$. pneumosintes.

The relatively large differences in DNA G $+C$ content and 16S rRNA gene sequence similarity between Dialister $\mathrm{E} 1$ and $D$. pneumosintes could be interpreted as indicating that these two taxa should be placed in different genera. However, because of the lack of phenotypic differences between the taxa, we propose that the novel taxon should be named as a novel species within the genus Dialister. We therefore propose the name Dialister invisus sp. nov. for strains formerly described as Dialister E1. There appear to be additional novel taxa in this branch of the phylogenetic tree.

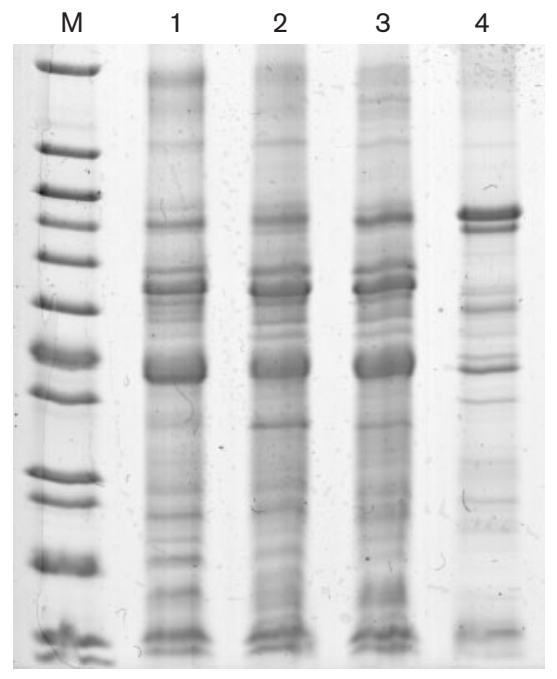

Fig. 3. Protein profiles of $D$. invisus and $D$. pneumosintes strains. Lanes: 1, D. invisus $\mathrm{E} 2.20 ; 2, D$. invisus $\mathrm{E} 7.25^{\top} ; 3, D$. invisus E9.48; 4, D. pneumosintes ATCC $33048^{\top} . \mathrm{M}$, Molecular mass markers $(6 \cdot 5,14 \cdot 2,20 \cdot 1,24,29,36,45,55$, $66,84,97 \cdot 4,116$ and $205 \mathrm{kDa})$.

Fig. 1 shows two cloned sequences, MCE7_134 and BS016, respectively recovered from an endodontic infection and subgingival plaque. The $16 \mathrm{~S}$ rRNA gene sequences of these clones were very similar ( $>99 \%$ relatedness): BS016 exhibited $91 \%$ relatedness to $D$. pneumosintes and $94 \%$ to D. invisus. They therefore appear to represent another novel Dialister taxon, but since no cultivable representatives of this group have yet been identified, no species proposal is possible at present.

\section{Emended description of Dialister (ex Bergey et al. 1923) Moore and Moore 1994}

Dialister (Di.a.lis'ter. Etymology unknown).

Cells are $0 \cdot 2-0 \cdot 4 \times 0 \cdot 3-0 \cdot 6 \mu \mathrm{m}$, Gram-negative, obligately anaerobic, non-motile, non-sporing and non-fermentative. Growth in broth media is only slightly turbid at best. Aesculin and urea are not hydrolysed; indole and catalase are not produced. There is no growth in $20 \%$ bile. The G $+\mathrm{C}$ content of the DNAs ranges from 35 to $46 \mathrm{~mol} \%$. The major cellular constituents of the type species $D$. pneumosintes include fatty acids $\mathrm{C}_{18: 1}$ cis- $9, \mathrm{C}_{16: 0}, \mathrm{C}_{18: 0}$ and $\mathrm{C}_{16: 1}$ cis-9. The cellular constituents of the other species in the genus, $D$. invisus, have not been determined. The type species is Dialister pneumosintes (Olitsky and Gates 1921) Moore and Moore 1994.

\section{Description of Dialister invisus sp. nov.}

Dialister invisus (in.vis'us. L. masc. adj. invisus unseen, referring to the lack of turbidity of broth cultures of this organism). 
The etymology, and therefore the gender, of the genus name is unknown. We therefore propose that the gender of the genus name be assigned as male, as allowed under Rule 65(3) of the Bacteriological Code, and hence the male form of the adjective selected as the specific epithet is given.

The description is based on six strains isolated from the human oral cavity. Cells are obligately anaerobic, nonmotile, Gram-negative, small cocci or ovoid cocci $(0 \cdot 3-$ $0 \cdot 4 \times 0 \cdot 3-0 \cdot 6 \mu \mathrm{m}$ ) that occur singly, in pairs, in short chains and in small clumps. After 7 days incubation on FAA plates, colonies are $0.5-0.7 \mathrm{~mm}$ in diameter, circular, entire and either translucent and umbonate or transparent and lowconvex with a narrow marginal, translucent fringe. Growth in broth media produces only a slight turbidity and is not visibly stimulated by the addition of $1 \%$ carbohydrates. Cells are asaccharolytic and only trace amounts of acetate and propionate are detected as end products of metabolism in peptone/yeast extract/glucose medium. Aesculin, arginine and urea are not hydrolysed. Indole and catalase are not produced. No growth in $20 \%$ bile. The $\mathrm{G}+\mathrm{C}$ content of the DNA of the type strain is $45 \mathrm{~mol} \%$.

The type strain is E7.25 $\left(=\right.$ CCUG $47026^{\mathrm{T}}=$ DSM $\left.15470^{\mathrm{T}}\right)$. Isolated from the human oral cavity in patients with endodontic and periodontal infections.

\section{Emended description of Dialister pneumosintes (Olitsky and Gates 1921) Moore and Moore 1994}

The description is as described by Moore \& Moore (1994), with the following additions: aesculin and urea are not hydrolysed; indole and catalase are not produced. There is no growth in $20 \%$ bile. The Rapid ID 32A profile is 0000010000 , which corresponds to a positive reaction for arginine arylamidase. The $\mathrm{G}+\mathrm{C}$ content of the DNA is $35 \mathrm{~mol} \%$.

\section{References}

Bergey, D. H., Harrison, F. C., Breed, R. S., Hammer, B. W. \& Huntoon, F. M. (1923). In Bergey's Manual of Determinative Bacteriology, pp. 271-272. Baltimore: Williams \& Wilkins.

Doan, N., Contreras, A., Flynn, J., Slots, J. \& Chen, C. (2000). Molecular identification of Dialister pneumosintes in subgingival plaque of humans. J Clin Microbiol 38, 3043-3047.

Downes, J., Munson, M. A., Radford, D. R., Spratt, D. A. \& Wade, W. G. (2002). Shuttleworthia satelles gen. nov., sp. nov., isolated from the human oral cavity. Int J Syst Evol Microbiol 52, 1469-1475.

Dymock, D., Weightman, A. J., Scully, C. \& Wade, W. G. (1996). Molecular analysis of microflora associated with dentoalveolar abscesses. J Clin Microbiol 34, 537-542.

Felsenstein, J. (1993). PHYLIP (phylogeny inference package) version 3.5c. Distributed by the author. Department of Genetics, University of Washington, Seattle, USA.

Ghayoumi, N., Chen, C. \& Slots, J. (2002). Dialister pneumosintes, a new putative periodontal pathogen. J Periodontal Res 37, 75-78.

Goldstein, E. J., Citron, D. M. \& Finegold, S. M. (1984). Role of anaerobic bacteria in bite-wound infections. Rev Infect Dis 6, S177-S183.
Holdeman, L. V. H. \& Moore, W. E. C. (1970). Outline of Clinical Methods in Anaerobic Microbiology. Blacksburg, VA: Virginia Polytechnic Institute and State University.

Holdeman, L. V. H., Cato, E. P. \& Moore, W. E. C. (1977). Anaerobe Laboratory Manual, 4th edn. Blacksburg, VA: Virginia Polytechnic Institute and State University.

Huß, V. A. R., Festl, H. \& Schleifer, K.-H. (1983). Studies on the spectrophotometric determination of DNA hybridisation from renaturation rates. Syst Appl Microbiol 4, 184-192.

Kroes, I., Lepp, P. W. \& Relman, D. A. (1999). Bacterial diversity within the human subgingival crevice. Proc Natl Acad Sci U S A 96, 14547-14552.

Maidak, B. L., Cole, J. R., Lilburn, T. G. \& 7 other authors (2001). The RDP-II (Ribosomal Database Project). Nucleic Acids Res 29, 173-174.

Milsom, S. E. (1997). Applications of $16 S$ rRNA analysis for the species and sub-species identification of oral bacteria. MSc thesis, University of Bristol, UK.

Milsom, S. E., Dymock, D. \& Wade, W. G. (1996). Isolation and characterisation of Dialister pneumosintes. J Dent Research 75, 1185.

Moore, L. V. H. \& Moore, W. E. C. (1994). Oribaculum catoniae gen. nov., sp. nov.; Catonella morbi gen. nov., sp. nov.; and Dialister pneumosintes gen. nov., comb. nov., nom. rev., anaerobic gram-negative bacilli from the human gingival crevice. Int J Syst Bacteriol 44, 187-192.

Munson, M. A., Pitt Ford, T., Chong, B., Weightman, A. J. \& Wade, W. G. (2002). Molecular and cultural analysis of the microflora associated with endodontic infections. J Dent Research 81, 761-766.

Olitsky, P. K. \& Gates, F. L. (1921). Experimental studies of the nasopharyngeal secretions from influenza patients. J Exp Med 33, 713-729.

Page, R. D. M. (1996). TreeView: an application to display phylogenetic trees on personal computers. Comput Appl Biosci 12, 357-358.

Paster, B. J., Boches, S. K., Galvin, J. L., Ericson, R. E., Lau, C. N., Levanos, V. A., Sahasrabudhe, A. \& Dewhirst, F. E. (2001). Bacterial diversity in human subgingival plaque. J Bacteriol 183, 3770-3783.

Rousee, J. M., Bermond, D., Piemont, Y., Tournoud, C., Heller, R., Kehrli, P., Harlay, M. L., Monteil, H. \& Jaulhac, B. (2002). Dialister pneumosintes associated with human brain abscesses. J Clin Microbiol 40, 3871-3873.

Slayne, M. A., Aldred, M. J. \& Wade, W. G. (1990). A rapid, semiautomated SDS-PAGE identification system for oral anaerobic bacteria. J Appl Bacteriol 68, 391-395.

Summanen, P., Baron, E. J., Citron, D. M., Strong, C. A., Wexler, H. M. \& Finegold, S. M. (1993). Wadsworth Anaerobic Bacteriology Manual, 5th edn. Belmont, CA: Star Publishing.

Thompson, J. D., Gibson, T. J., Plewniak, F., Jeanmougin, F. \& Higgins, D. G. (1997). The CLUSTAL_X windows interface: flexible strategies for multiple sequence alignment aided by quality analysis tools. Nucleic Acids Res 25, 4876-4882.

Wade, W. G., Gray, A. R., Absi, E. G. \& Barker, G. R. (1991). Predominant cultivable flora in pericoronitis. Oral Microbiol Immunol 6, 310-312.

Wade, W. G., Downes, J., Dymock, D., Hiom, S. J., Weightman, A. J., Dewhirst, F. E., Paster, B. J., Tzellas, N. \& Coleman, B. (1999). The family Coriobacteriaceae: reclassification of Eubacterium exiguum (Poco et al. 1996) and Peptostreptococcus heliotrinreducens (Lanigan 1976) as Slackia exigua gen. nov., comb. nov. and Slackia heliotrinireducens gen. nov., comb. nov., and Eubacterium lentum (Prevot 1938) as Eggerthella lenta gen. nov., comb. nov. Int J Syst Bacteriol 49, 595-600.

Willems, A. \& Collins, M. D. (1995). Phylogenetic placement of Dialister pneumosintes (formerly Bacteroides pneumosintes) within the Sporomusa subbranch of the Clostridium subphylum of the grampositive bacteria. Int J Syst Bacteriol 45, 403-405. 